\title{
Call me - mobile telephone blues
}

The development of mobile telephone communication technology and its availability on a worldwide scale has been widely recognised as a force for good. There have been, however, concerns about the possible harmful effects of prolonged exposure to this technology. ${ }^{1,2}$ Two articles in this issue investigate possible harmful effects of mobile telephone use. Seckin and colleagues investigate the possible effects of radiofrequency radiation on cochlear development in a rat model. ${ }^{3}$ They conclude that cellular structural damage in the developing cochlea can occur with radiofrequency radiation exposure. A previous study by Kayabasoglu and colleagues published in The Journal of Laryngology \& Otology had shown that exposure of the newborn and adult rat cochlea to electromagnetic fields associated with mobile telephones had no adverse effects. ${ }^{2}$ Apart from the auditory apparatus, another body tissue in close proximity to mobile telephones during use is the salivary glands. In another article, Hashemipour and colleagues investigate the possible effects of mobile telephone electromagnetic radiation on salivary gland function. ${ }^{4}$ They found that the side of dominant mobile telephone use was associated with differences in salivary flow rate and parotid gland salivary concentrations in right-dominant users.

The facial nerve is the subject of two articles in this issue. Firstly, the condition of geniculate neuralgia is reviewed by Tang and colleagues. ${ }^{5}$ This disorder is a rare form of cranial nerve neuralgia originating from the nervus intermedius. The authors conclude that, in cases resistant to medical therapy, intratemporal division of the cutaneous branches of the facial nerve can be justified, although because of small numbers evidence-based data are difficult to identify. With increasing use of non-surgical and conservative management strategies, surgery for patients with vestibular schwannoma is far less common than previously thought. ${ }^{6}$ Hence, it is unlikely that a case series as large as the one reported by Moffat and colleagues will be repeated. ${ }^{7}$ Moffat et al. report on the factors affecting final facial nerve outcome following vestibular schwannoma surgery, concluding that tumour size and operation year were significant predictors of facial nerve outcome. The surgical learning curve was steepest for the first 50 patients.

\section{ROBIN YOUNGS EDWARD FISHER Senior Editors}

\section{References}

1 Khalil S, Nunez DA. Do mobile 'phones have a detrimental impact on auditory function? J Laryngol Otol 2006;120:822-6

2 Kayabasoglu G, Sezen OS, Eraslan G, Aydin E, Coskuner T, Unver S. Effect of chronic exposure to cellular telephone electromagnetic fields on hearing in rats. J Laryngol Otol 2011;125: 348-533

3 Seckin E, Suren Basar F, Atmaca S, Kaymaz FF, Suzer A, Akar A et al. The effect of radiofrequency radiation generated by a Global System for Mobile Communications source on cochlear development in a rat model. J Laryngol Otol 2014;128:400-405

4 Hashemipour MS, Yarbakht M, Gholamhosseinian A, Famori H. Effect of mobile phone use on salivary concentrations of protein, amylase, lipase, immunoglobulin A, lysozyme, lactoferrin, peroxidase and C-reactive protein of the parotid gland. J Laryngol Otol 2014;128:454-462

5 Tang IP, Freeman SR, Kontorinis G, Tang MY, Rutherford SA, King AT et al. Geniculate neuralgia: a systematic review. J Laryngol Otol 2014;128:394-399

6 Gimsing S. Vestibular schwannoma: when to look for it? J Laryngol Otol 2010;124:258-64

7 Moffat DA, Parker RA, Hardy DG, Macfarlane R. Factors affecting final facial nerve outcome following vestibular schwannoma surgery. J Laryngol Otol 2014;128:406-415 